\title{
Amazigh 92: por la creación del Centro de Estudios Amazigh *
}

Hussein Bouzalmate

Resumen

La ciudad de Melilla, ubicada espacialmente en la bisagra de dos continentes históricos, ligada a la noción secular de mediterraneidad, y cruzada en este final del siglo $X X$, por la impronta de sus peculiaridades pluriétnicas, aparece como el lugar idóneo para el establecimiento del Centro de Estudios Amazigh, que podría intentar acabar con la marginalidad histórica de una comunidad que a pesar de haber sido durante siglos protagonista de importantes capítulos de la historia humana, sigue caminando a la busca de sus señas de identidad.

Antes de empezar quisiera detenerme un poco para explicar las razones que me han inducido a elegir el título de Amazigh 92.

El título que tenía previsto, en un principio, es el que figura en el programa y el cual había comunicado a la coordinadora Mimona

(*) Conferencia pronunciada durante las II Jomadas de la Cultura Tamazigh. celebradas en Melilla, en abril de 1992. 
Abdeselam - a quien de paso felicito por el esfuerzo realizado en la organización de este encuentro-, el tema lo merece. La razón del cambio fue debido a una serie de circunstancias personales, las que me llevaron a titular esta charla: Amazigh 92, con un marcado matiz reivindicativo que no quiero ocultar.

A continuación voy a referirme - de manera breve- al motivo del cambio - que en realidad es sólo formal- porque el contenido del trabajo no ha sufrido variación alguna.

En el transcurso de una conferencia que tuvo lugar en Madrid, el pasado mes de febrero en la Sociedad de Estudios Internacionales (S.E.I.), el conferenciante, que ese día era el señor Luis Yáñez-Barnuevo, Presidente de la Comisión y de la Sociedad Estatal del Quinto Centenario disertaba sobre Labor de la Comisión y de la Sociedad Estatal del Quinto Centenario:

Le planteé que dentro de los actos programados para la conmemoración del Quinto Centenario del Descubrimiento de América no se había hecho nada por el colectivo bereber. Le argumenté que se trataba de una ausencia significativa habida cuenta del despilfarro que supone el 92 para las arcas del estado español. La respuesta del señor Yáñez no se hizo esperar, fue escueta y lacónica, diciendo - cito palabras textuales: "Tomo nota".

Espero que se tome realmente nota y se organicen actos sobre la cultura y civilización bereber que bien merecen ser sacadas a la luz.

Hecha esta breve aclaración, a continuación voy a referirme - de manera somera - a lo emblemático que es el año 1992 en cuya programación se viene trabajando desde hace una década, y en la que no figuramos como bien corresponde.

Todos somos conscientes de lo apretada que está la agenda oficial de la España del 92: no busco afán de protagonismo para los bereberes.

- La Exposición Universal de Sevilla (Expo 92) que abrio sus puertas el pasado lunes 20 de abril.

- La Olimpíada de Barcelona 92 cuya competición empezará el verano próximo (Barcelona 92), el día 25 de julio.

- Madrid, Capital Europea de la Cultura (Madrid 92).

Si todos los acontecimientos que acabo de mencionar tienen la particularidad de ser actos cuya celebración en España es accidental, no obstante los del Quinto Centenario son de obligada conmemoración 
porque es una efemérides que marca un hito importante en la Historia Universal.

Mi proposito en la presente comunicación no es entrar en la valoración, ni tampoco voy a detenerme en la polémica que ha suscitado la conmemoración del Descubrimiento de América. Es sabido por todos que muchas plumas se han desatado, en algunos casos con bastante acritud, a ambas orillas del Atlántico, bien en pro o en contra (pienso en un escritor de la talla del colombiano Gabriel García Márquez) (el término Conquista tuvo también su polémica). Mi intención es resaltar la indiscutible trascendencia que tuvo el Descubrimiento del Nuevo Mundo y los grandes cambios que ha generado en el devenir de la Historia y de la Humanidad. Estos hechos son incuestionables.

Dentro de esta caja china que es el 92 , aparte de las ya enumeradas, son varias las cosas que se conmemoran:

Por una parte en 1992 se cumple el Quinto Centenario de la primera gramática de la lengua española elaborada por Antonio Nebrija. Este aniversario se ve plasmado con la creación del Instituto Cervantes. España emula lo que mucho antes hicieron Francia con la Alliance Française, Inglaterra con el British Council y Alemania con el Goethe Institute. La nueva política española va encaminada a potenciar la presencia de la lengua española en el mundo.

1492 es también el año en el que se decreta la expulsión de árabes y judíos, poniendo fin a la presencia de estas dos importantes comunidades en España.

Entre los actos programados para dicha conmemoración cabe destacar dos: Sefarad 92, un claro intento de recuperar el legado judío de España. Dentro de esta línea cabe mencionar que la exposición que tiene lugar en Toledo es un ejemplo de cómo reconciliar España con su pasado semita. Amén de otros actos que se van a celebrar en distintos puntos de la Península, sobre todo lo que atañe a Sefarad 92.

La otra conmemoración es Al-Andalus 92 . La emblemática ciudad de Granada ha sido elegida como sede de una exposición permanente del legado árabe en España. Sobre esta última me voy a detener un poco porque fue el motivo de la interpelación que le hice al señor Yánez.

Dentro de los actos oficiales que se van a celebrar bajo el rótulo de Al-Andalus 92, no hay ninguno que aborde el legado bereber en la Península (hago una excepción para romper una lanza en favor de los 
organizadores de este encuentro). La injusticia y la negligencia a la que quedan relegados los bereberes en el marco de los programas conmemorativos, es a todas luces injustificable. Esto explica el título que le he dado a esta modesta comunicación.

No quiero que se entiendan estas palabras en tono provocativo; no es mi propósito levantar rencillas, sino simplemente dejar patente mi indignación y el afán reivindicativo que me anima. Con tristeza observo, que una vez más estamos pasando desapercibidos. Parece ser que nuestro sino ha sido y sigue siendo el de estar "al margen de la Historia".

En el marco de los actos que conmemoran la expulsión de 1492, sólo se hace referencia a árabes y judíos. No se menciona para nada a los bereberes que también sufrieron los mismos designios y la misma suerte: la expulsión de su tierra.

Sobre la óptica oficial se cierne una vez más la miopía histórica y la generalización sistemática. Se olvida que la invasión de la Península tuvo en la persona de Tarik su punta de lanza, también se olvida el rico legado bereber de Al-Andalus: arquitectura, arte marcial, etc.

Todo esto hace que el 92 sea una fecha clave para reivindicar la creación de un Centro de Estudios Amazigh (C.E.A.).

Soy consciente de las susceptibilidades que pueda despertar la creación de un CEA tanto por parte de España como de Marruecos; estas tentativas siempre se han visto con recelo. Sin embargo, hay que aprovechar esta coyuntura histórica que se nos presenta ya que es un marco inmejorable para que se vaya abriendo paso y se haga realidad este anhelo, que desde hace algún tiempo me viene siguiendo. Creo que en el fuero interno de muchos de los aquí presentes late esta misma idea.

La experiencia me ha demostrado que no basta con decir las cosas una sola vez. Hay que insistir, y lo paradojico del caso es que en la insistencia reside el convencimiento y la firmeza de la causa por la que se combate. Parece ser que los responsables se olvidan de ello. No debemos desalentarnos si al principio nos parece que predicamos en el desierto.

Con toda honestidad, pienso que con la creación del CEA, se dará cuerpo a una realidad palpable. A las puertas del siglo XXI nos encontramos ante una comunidad que no tiene su verdadero reflejo en la sociedad, tanto en los niveles cultural como político (aun situándonos en la hipótesis de que este reflejo exista, no corresponde a la dimensión e 
importancia que debe tener). Esto me recuerda un poco lo que Miguel de Unamuno llamaba la intra-historia, en réplica a la historia oficial.

Desgraciadamente todavía formamos parte de esa intrahistoria. Si hasta hace poco el problema era el de la documentación, ahora se trata de reivindicar una identidad.

Se me podrá objetar que en Melilla existen asociaciones culturales (e incluso se ha creado recientemente el Partido HispanoBereber). Aunque no conozco bien el tema porque vivo alejado de la ciudad, no obstante me voy a referir, aunque sea a vuelapluma, a dicha cuestion.

Si el derecho de asociación es un derecho muy respetable, no cabe la menor duda que cuando se trata de Cultura (con c mayúscula) tienen que primar otros parámetros que están por encima de nosotros. La cultura es un todo indivisible y nadie puede hacerse portavoz de ella para fines partidistas. equivocado- a:

La proliferación de asociaciones se debe $-y$ espero estar

$\left.1^{\circ}\right)$ intereses partidistas inmediatos;

$2^{\circ}$ ) protagonismo personal; $y$,

$3^{\text {) }}$ afán de lucro mediante las subvenciones a las asocia-

ciones.

Se equivoca quien tome estas palabras como un ataque a las asociaciones. Digo esto con afán de que se mejoren las cosas.

La creación del CEA se impone por múltiples razones; y, en este contexto, Melilla reune todas las condiciones para erigirse en su epicentro (otra batalla es incluir la temática bereber en la enseñanza).

En esta ciudad, convergen todos los ingredientes esenciales: población bereber, creciente interés por el tema; y algo muy importante como es la fuente oral, aspecto al que dedicaré más adelante algunas palabras.

Melilla reune el objeto y el sujeto de la historia. Por consiguiente está destinada a jugar, en este terreno, el verdadero papel que le corresponde. La ciudad debe aprovechar su coyuntura historica y no desperdiciar la oportunidad que se le presenta. Tiene que hacer gala de talante y demostrar que es bien merecedora de albergar el CEA. Su posición geoestratégica (punto de enlace entre España y Africa) y su condición pluriétnica (crisol de varias culturas) la convierten en el marco ideal. 
Huelga decir que una empresa de esta envergadura es imposible llevarla a cabo de manera individual, requiere un esfuerzo colectivo. Hay que pegar en las puertas de organismos oficiales y privados, entidades culturales y personalidades, etc. Para la creación del CEA se debe recurrir a todo tipo de ayudas con tal de obtener su carta de naturaleza para ello, ahora me voy a detener para explicar, a grandes rasgos, las coordenadas que deben regir el Centro. Todo ello visto desde un marco teórico.

El primer requisito que quiero plantear, y que a mi juicio es capital, es que el Centro debe ser apolítico e independiente. Cuando hablo de apolítico, no me gustaria que se malinterpretara el concepto. En mi opinión no existe el grado cero en política. El ser humano, por naturaleza, es un ser político, en la medida en que vive de y en sociedad. La política está estrechamente ligada a su vida cotidiana. Cuando hablo de apolítico, me refiero a que debe ser apartidista e independiente.

El CEA no tiene porqué ser apolítico - pobre de él si lo essino apartidista; no permitiendo ningún tipo de manipulación porque lo que está en juego es algo que trasciende a todos nosotros. Creo que si no se ponen estas dos reglas como norma de conducta, difícilmente se puede augurar un horizonte al CEA.

El Centro ha de ser un foro abierto donde tengan eco todas las sensibilidades. Ha de incitar a estudiantes, profesores, intelectuales, y a todos aquellos que quieran emprender esta nueva singladura, a la investigación. El CEA será un punto de encuentro y de debate.

Otra de las tareas capitales que tendrá por misión el CEA es la de recopilar material bibliográfico sobre el mundo bereber. Por desgracia, todos los estudiosos que han trabajado sobre cuestiones africanas sea sobre el Magreb, el Sáhara (en toda su extensión), Sudán o el Nilo (regiones bereberes), han coincidido en recalcar la carencia de estudios serios y la falta de trabajos metódicos sobre el conjunto de la sociedad bereber. De ahí que urja la creación del CEA para que; en primer lugar, recopile el material disperso que existe sobre el mundo bereber; en segundo lugar, ser un foco de irradiación y difusión de la civilización bereber; y en tercer lugar, fomentar la creación de trabajos, desde diferentes perspectivas, tendentes a enriquecer nuestra cultura en todos los ámbitos.

Para ello se debe echar mano a las múltiples disciplinas humanísticas como antropología, sociología, etnología, historia, lingüística, 
literatura, y un largo etcétera. Se hace imprescindible la colaboración entre las diferentes disciplinas, para que cada cual desde su optica, aporte su granito de arena en aras de una mejor comprensión de nuestra cultura. El tema requiere estudios multidisciplinarios para asf ir esbozando con rigor y espíritu científico los lindes de la identidad bereber.

Se tiene que hacer énfasis en los aspectos tanto históricos como actuales (desde la Prehistoria hasta la época actual). Un Centro como el que se pretende no debe encerrarse en el estudio del pasado sin tener ojos para ver la realidad presente. Hay que estar abiertos a nuestra época y al pulso de la sociedad en la que vivimos con el fin de rendirle un mejor servicio.

También merecen especial atención aspectos que pueden ir de la religión, al arte, la economía, la política, etc.

La artesanfa tiene que tener un lugar preponderante, así como la economía tradicional, la astrología, las fiestas, la organización del espacio. Es decir, todo aquello que engloba lo que hoy llamamos etnología y geografía humanas. El Centro tendrá por misión resaltar la peculiaridad del pueblo bereber y su innegable mediterraneidad.

Otro aspecto importante a tener en cuenta es el lingüístico porque es el que identifica y refleja la idiosincrasia amazigh. Pero en este terreno hay que evitar disquisiciones o valoraciones de todo tipo y salir al paso a aquellos que piensan que el bereber no es una lengua sino un dialecto.

También están los que opinan que es una lengua sin escritura. Y yo me pregunto iacaso todas las lenguas que hoy día conocemos no fueron en su origen lenguas habladas?. Además, gracias a los avances de la lingüística durante el presente siglo se puede transcribir cualquier lengua. Sospecho que hay interés en que el bereber siga en su letargo. Hay que hacer valer el derecho de una "inmensa minoria" en el uso de su lengua, dándole los instrumentos necesarios para que lleve a buen término su labor.

Para hacer un poco de historia-ficción diré que si el Rif hubiese sido colonizado por Francia (aunque todo hecho colonial es deplorable), en la actualidad tendríamos una extensa bibliografía sobre nuestro legado cultural, similar al existente sobre Kabilia argelina (digo esto independientemente de los intereses e ideologfa de estos escritos, no entro en juicios de valor). Si trasladamos la cuestión a Marruecos obtendremos el mismo resultado. 
Dentro del CEA se podrá fomentar la creación de un archivo de fuentes orales, así como de videoteca y fonoteca. Este tipo de testimonio es de vital importancia porque nos permitirá recoger las distintas manifestaciones de nuestra cultura: bodas, nacimientos, romerías, duelos, o simplemente imágenes de la vida cotidiana.

No cabe duda de que es un proyecto ambicioso y apasionante al que todos están invitados. El afán de buscar la peculiaridad de nuestra cultura no está reñido con la convivencia y el diálogo. El respeto y la tolerancia deberán estar por encima de todo.

Pienso que con la creación del CEA se institucionalizará una realidad que pide a gritos su reconocimiento. En este sentido, no faltará quien piense que es una reivindicación oportunista. A éstos les digo, que el tema bereber no está de moda. Es una concepción de la vida, una condición secular de un pueblo que a lo largo de la historia ha tenido que forjar su identidad ante todo tipo de adversidades. Desde la antigüedad faraónica datan las referencias al mundo bereber. En el Antiguo Imperio, los egipcios mantuvieron relaciones, sea en tiempos de paz o en tiempos de guerra, con los bereberes. A pesar de la vicisitudes de la Historia: invasiones, conquistas, asimilaciones, etc., los bereberes siguen existiendo.

Hoy día se habla la lengua bereber en varios países del Norte de Africa: del Mediterráneo al Níger, y del Atlántico al Nilo. Aunque bien es cierto que no toda la región es bereberofona, el árabe es la lengua oficial y del estado (excepto Senegal y Tchad). En las constituciones de los países con población bereber, como Marruecos, Argelia o Túnez, por no citar mas que a los de mayor porcentaje, tampoco se recoge esta diversidad, que a fin de cuentas es su riqueza. Esta omisión tiene su aspecto más trágico: la guerra de los tuareg.

Pero no preciso decir que, para llevar a cabo esta empresa, la ética que debe marcar las pautas se puede resumir en: humildad, perseverancia y amor por lo que se hace. Todos estos requisitos son imprescindibles si queremos tener credibilidad. E, incluso, me atrevo a añadir la generosidad.

Quisiera acabar esta exposición diciendo que lo triste de nuestro sino es que seguimos estando marginados de las esferas oficiales. Pero no por ello vamos a mermar nuestros esfuerzos en dar a nuestra entidad el lugar que le corresponde.

Desde la antigua Grecia se distinguía con claridad entre ciudad y barbarie. Hoy día, salvando las diferencias de tiempo y espacio, 
seguimos siendo un núcleo periférico. Pero una cultura y una sociedad determinadas se consideran vivas por los actores dinámicos que las integran. A nosotros nos toca - ya que el momento histórico nos llama a ello- demostrar la viveza de nuestra cultura. Hay que sacarla del letargo, pero sin sobresaltos, despertar conciencias, hablar de lo que hiere si es necesario, único remedio de salvar las adversidades. Es tiempo de que la expresión o el vocablo amazigh responda a su verdadera etimología que es la de: hombre libre.

Voy a terminar esta exposición diciendo que las ideas vertidas por mi, son reflexiones (un esbozo de proyecto) a las que estáis todos invitados. No pretendo ni aspiro a que se conviertan en una norma de conducta. Nadie es profeta en su tierra. Simplemente he querido abrir un debate para que todos reflexionemos en voz alta, y convengamos en la necesidad de crear el CEA, de lograrlo me daré por satisfecho. Muchas gracias. 